Tacit Collusion and Market Concentration under Network Effects

Rupayan Pal and Marcella Scrimitore

Indira Gandhi Institute of Development Research, Mumbai April 2016

http://www.igidr.ac.in/pdf/publication/WP-2016-010.pdf 


\title{
Tacit Collusion and Market Concentration under Network Effects
}

\author{
Rupayan Pal and Marcella Scrimitore \\ Indira Gandhi Institute of Development Research (IGIDR) \\ General Arun Kumar Vaidya Marg \\ Goregaon (E), Mumbai- 400065, INDIA \\ Email(corresponding author): rupayan@igidr.ac.in
}

\begin{abstract}
In an infinitely repeated Cournot game with trigger strategy punishment, we demonstrate that the relationship between market concentration and collusion sustainability depends on the strength of network externalities. The latter is shown to interact with the number of firms and to affect the profitability of cooperation vs. competition, which delivers the result, challenging conventional wisdom, that lower market concentration can make collusion more stable.
\end{abstract}

Keywords: Collusion, market concentration, network effects

JEL Code: L13, L14, L41 


\title{
Tacit Collusion and Market Concentration under Network Effects
}

\author{
Rupayan Pal \\ Indira Gandhi Institute of Development Research (IGIDR) \\ Film City Road, Santosh Nagar, Goregaon (E) - Mumbai, 400065, India. \\ Email: rupayan@igidr.ac.in \\ Marcella Scrimitore \\ University of Salento, Ecotekne, via per Monteroni - Lecce, 73100, Italy. \\ Rimini Centre for Economic Analysis, Rimini, Italy \\ Email: marcella.scrimitore@unisalento.it
}

\begin{abstract}
In an infinitely repeated Cournot game with trigger strategy punishment, we demonstrate that the relationship between market concentration and collusion sustainability depends on the strength of network externalities. The latter is shown to interact with the number of firms and to affect the profitability of cooperation vs. competition, which delivers the result, challenging conventional wisdom, that lower market concentration can make collusion more stable.
\end{abstract}

\section{Jel Codes}

L13, L14, L41

Keywords

Collusion, market concentration, network effects

Corresponding author: Marcella Scrimitore, Dipartimento di Scienze dell'Economia, University of Salento. Ecotekne, via per Monteroni, I-73100 Lecce, Italy. The Rimini Centre for Economic Analysis. Telephone: +390832298772; fax: +390832298757; email: marcella.scrimitore@unisalento.it. 


\section{Introduction}

Cartel prosecution is at the core of competition policy and the understanding of cartel behavior in oligopoly markets is a major concern in Industrial Organization. Studies on tacit (or non-cooperative) collusion provides a game-theoretic foundation of cartel stability. ${ }^{1} \mathrm{By}$ modeling firm interactions as a infinitely repeated game, collusive behavior emerges as a sub-game perfect Nash equilibrium, provided that the discount factor of future firm payoffs is large enough. In line with the view of the Chicago School, economic theory sustains the idea that market concentration facilitates collusion (Selten. 1973; Brozen, 1977; Levenstein and Suslow, 2006). ${ }^{2}$ The argument is also supported by empirical evidence (Fraas and Greer, 1977; Davies et al., 2011, among others) and experimental evidence (Huck et al., 2004; Fonseca and Normann, 2008).

This paper examines the role of market concentration in sustaining collusion when consumers' preferences exhibit network externalities (or network effects), namely when their utility increases as market gets larger. The latter have been shown to have relevant implications for economic analysis and antitrust enforcement: ${ }^{3}$ indeed, they can represent a source of firm success and market power in network industries, such as telecommunications and utilities, and to play a considerable role in the process of technology adoption and decision-making on network goods' pricing, compatibility and connectivity. With the exception of the preliminary works by Ruhmer (2011) and Boffa and Filistrucchi (2014), which examine platforms' incentives to collude on two-sided markets and cross network

\footnotetext{
${ }^{1}$ See Martin (2006) for a distinction drawn between collusion as the outcome of a non-cooperative game and the antitrust concept of collusion.

${ }^{2}$ As asserted in Levenstein and Suslow (2006); 'cartels are much more likely to succeed in concentrated industries than in less concentrated ones'; and moreover: 'industry concentration makes collusion easier both by simplifying the coordination issues and by increasing firms' gains from collusion'.

${ }^{3}$ See Shy (2011) for a recent survey on the economics of network effects and Economides (2009) for an analysis of antitrust issues in network industries. See also Birke (2009) for an empirical literature review in the field, and Devetag (2003) and Ruffle et al. (2015) for experimental evidence on the concept of critical mass in network markets.
} 
effects, research on cartel stability under network effects remains scarce. ${ }^{4}$ This paper contributes to such research by studying the conditions for collusion stability in a Cournot oligopoly with network effects, when collusion is enforced via a trigger strategy (Friedman, 1971). We demonstrate that firm incentives to collude depend on the strength of network externalities, the latter interacting with the number of firms in making collusion more or less stable as market becomes more concentrated. In particular, we find that, unless the strength of network externalities is very low, collusion stability increases (decreases) with the number of firms when the latter is sufficiently low (high).

\section{The Model}

We consider that there are $k$ firms producing homogeneous network goods. Each firm incurs constant marginal(average) cost of production $c(\geq 0)$. Firms either compete in terms quantity or form a grand coalition. The market demand function is assumed to be as follows

$$
p=a+n\left(\sum_{i=1}^{k} y_{i}\right)-\sum_{i=1}^{k} x_{i}
$$

where $p$ denotes price and $x_{i}$ denotes the quantity of the good produced by firm $i(=$ $1,2, \ldots, k) . y_{i}$ denotes the consumers' expectation regarding firm $i$ 's sales. $\alpha(>c)$ and $n \in[0,1)$ are demand parameters. Note that $\frac{\partial p}{\partial y_{i}}=n$, i.e., if $n>0$, the marginal willingness to pay for the good increases with the increase in consumers' expectation regarding firm $i$ 's total sales. Thus, higher value of $n$ indicates stronger network externalities. $n=0$ corresponds to the case of non-network goods.

\footnotetext{
${ }^{4}$ While Boffa and Filistrucchi (2014) focus on how network effects shape the collusive optimal price structure, Ruhmer (2011), by examining the different impact of stronger network effects on the gains from collusion and the gains from deviation, reveals that the latter always dominates the former, which makes collusion harder to sustain.
} 


\subsection{Cournot Competition}

Cournot equilibrium output and profit of firm $i$ are as follows.

$$
\begin{aligned}
x_{i}^{C N} & =\frac{a-c}{1+k-k n} \\
\pi_{i}^{C N} & =\frac{(a-c)^{2}}{(1+k-k n)^{2}} ; i=1,2 \ldots k .
\end{aligned}
$$

\subsection{Collusion}

Output and profit of firm $i$ under full collusion are as follows.

$$
\begin{aligned}
x_{i}^{C C} & =\frac{a-c}{k(2-n)} \\
\pi_{i}^{C C} & =\frac{(a-c)^{2}}{k(2-n)^{2}} ; i=1,2, \ldots k .
\end{aligned}
$$

\subsection{Incentive to Collude}

A firm has incentive to collude, if its profit under collusion is greater than its profit under competition, i.e., if

$$
\pi_{i}^{C C}>\pi_{i}^{C N} \Rightarrow \frac{(k-1)(a-c)^{2}\left(k(1-n)^{2}-1\right)}{k(2-n)^{2}(1+k-k n)^{2}}>0 \Rightarrow k>\frac{1}{(1-n)^{2}}=\hat{k}(n) .
$$

It is evident that $\hat{k}(0)=1$. That is, in the case of non-network goods oligopoly $(n=0)$, a firm has incentive to collude regardless of the number of firms in the market.

In contrast to the case of non-network goods oligopoly, under network goods oligopoly the number of firms in the market must be greater than a critical level, $\hat{k}(n)$, for collusion to be more profitable than competition. Further, note that $\frac{\partial \hat{k}(n)}{\partial n}>0$, i.e, stronger the network externalities, greater is the required number of firms in the market for collusive profit to be larger than profit under competition. 


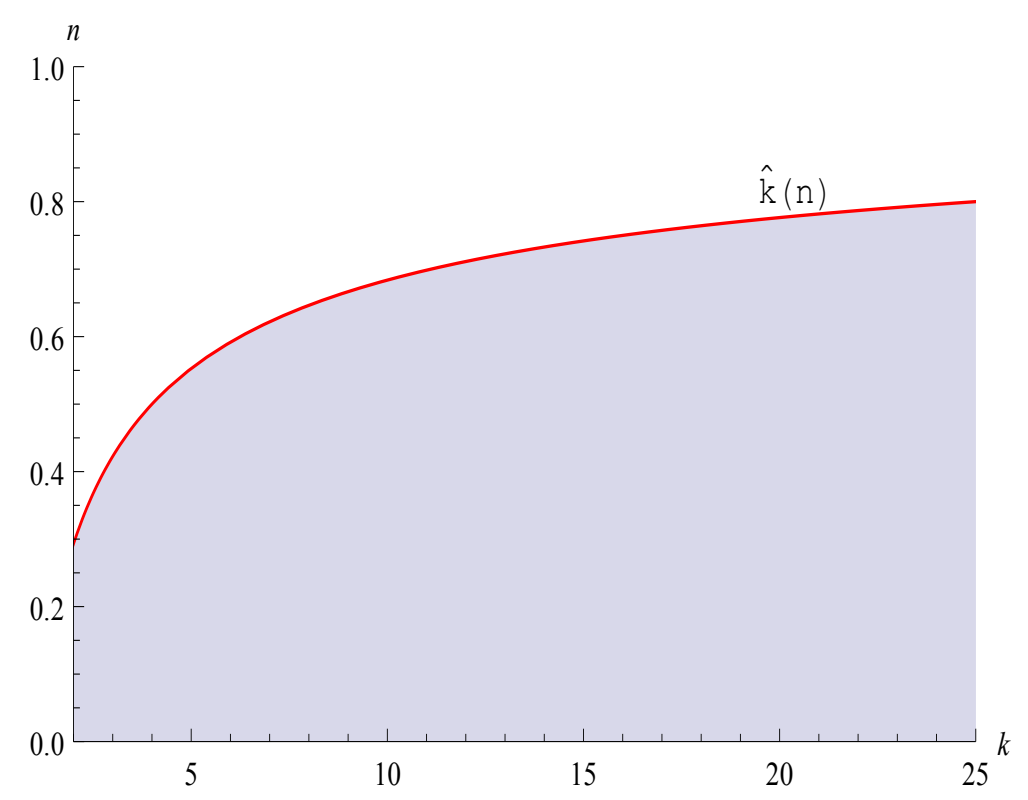

Figure 1: Collusion Incentive

The red curve in Figure 1 depicts $k=\hat{k}(n)$ in the $k n$-plane. In the region below the red curve, i.e., in the shaded region, we have $k>\hat{k}(n)$; while the opposite is true in the region above the red curve. That is, for each $(k, n)$ combination in (outside) the shaded region, a firm obtains higher (lower) profit in the case of collusion compared to that under competition.

For example, if $n=0.3$, in order to have incentive for collusion there must be at least three firms in the market. If $n=0.43$, the required number of firms for collusion to be more profitable that competition is four. If $n=0.9$, the minimum number of required firms to have incentive to collude is as large as 100. Clearly, collusion is less likely in the presence of stronger network externalities. This is a new result.

Proposition 1: Unlike as in the case of non-network goods oligopoly, a firm's profit under collusion need not necessarily be higher than that under competition in the case of network goods oligopoly. The number of firms in network goods oligopoly needs to be sufficiently large for the existence of incentive to collude. The stronger the network externalities, the 
greater the required number firms to have incentive to collude.

The intuition behind Proposition 1 is as follows. From (1) it follows that the outward shift of the demand curve due to network externalities is greater in the case of stronger network externalities (higher $n$ ). Also, for any given strength of network externalities $(n)$, the higher is expected industry output, the greater is the outward shift of demand curve. Now, industry output is higher under competition than under collusion. That is, for any given $n$, competition leads to higher expected output and thus greater outward shift of the demand curve compared to that under collusion. It implies that, due to network externalities, there is a higher gain from competition than collusion.

Also, note that under collusion total industry output and profit remain invariant to the number of firms. Thus, under collusion, the extent of outward shift of the demand curve due to network externalities does not depend on the number of firms; only the industry profit gets divided among greater number of firms, if there are more firms. In contrast, under competition, the greater the number of firms, the greater the outward shift of the demand curve for any given $n$, which has positive impact on firms' profit under competition. On the other hand, the greater the number of firms, the higher the intensity of competition, which has a negative impact on firm's profit. The net effect of the number of firms on firm's profit is negative.

Overall, the stronger the network externalities (i.e., higher the $n$ ), the larger the gain from competition relative to the gain from collusion, unless competition is sufficiently intense (i.e., unless the number of firms is sufficiently large).

\subsection{Deviation from Collusive Agreement}

Now suppose that firm 1 deviates from the collusive agreement. Then, output and profit of the deviating firm, i.e., firm 1 are as follows. 


$$
\begin{aligned}
& x_{1}^{C D}=\frac{(a-c)(1+k-n)}{k(2-n)^{2}} \\
& \pi_{1}^{C D}=\frac{(a-c)^{2}(1+k-n)^{2}}{k^{2}(2-n)^{4}}
\end{aligned}
$$

In this case output and profit of each of the $(k-1)$ non-deviating firms are as follows.

$$
\begin{aligned}
x_{i}^{C D} & =\frac{a-c}{k(2-n)} \\
\pi_{i}^{C D} & =\frac{(a-c)^{2}(1+k-n)}{k^{2}(2-n)^{3}} ; i=1,2, \ldots . k .
\end{aligned}
$$

\subsection{Stability of Collusion: Trigger Strategy}

Given the discount factor $\delta(0<\delta<=1)$, collusion is stable iff

$$
\begin{aligned}
& \pi_{i}^{C C}+\frac{\delta}{1-\delta} \pi_{i}^{C C} \geq \pi_{i}^{C D}+\frac{\delta}{1-\delta} \pi_{i}^{C N} \\
\Rightarrow & \frac{\delta}{1-\delta} \geq \frac{\pi_{i}^{C D}-\pi_{i}^{C C}}{\pi_{i}^{C C}-\pi_{i}^{C N}}=\frac{\left[k-(1-n)^{2}\right](1+k-k n)^{2}}{k(2-n)^{2}\left[k(1-n)^{2}-1\right]} .
\end{aligned}
$$

Note that collusion is less stable, if $\delta$ is higher. Let $\Delta=\frac{\delta}{1-\delta}$. Clearly, (a) $\Delta=0$, if $\delta=0$ and (b) $\frac{\partial \Delta}{\partial \delta}>0$. From (12), it follows that $\Delta>0$ iff $k>\frac{1}{(1-n)^{2}}=\hat{k}(n)$. That is, whenever there is an incentive to collude, there exists a discount factor $\delta^{*} \in(0,1)$ such that collusion is stable for all $\delta \geq \delta^{*}$, i.e., for all $\Delta>\Delta^{*}=\frac{\delta^{*}}{1-\delta^{*}}$. Now, $\frac{\partial \Delta^{*}}{\partial k}=$ $\frac{(1-n)(1+k-k n)\left[k^{3}(1-n)^{2}-k^{2}(3-n)+k(3-2 n)(1-n)^{2}+n-1\right]}{k^{2}(2-n)^{2}\left[\left(k(1-n)^{2}-1\right]^{2}\right.}$. Since $n \in[0,1)$ and $k \geq 2$, Sign $\left[\frac{\partial \Delta^{*}}{\partial k}\right]=$ $\operatorname{Sign}\left[k^{3}(1-n)^{2}-k^{2}(3-n)+k(3-2 n)(1-n)^{2}+n-1\right]$. Let $f(n, k)=k^{3}(1-n)^{2}-k^{2}(3-$ $n)+k(3-2 n)(1-n)^{2}+n-1$. It is easy to check the following.

(a) $f(n, k)$ is a continuous differentiable function in $n$, for any given $k$.

(b) For any given $k(\geq 2), f(n, k)$ has a unique minimum at $n=\frac{1}{6}\left(k^{2}+7\right)-\frac{1}{6} \sqrt{\frac{k^{5}+2 k^{3}+6 k^{2}+k+6}{k}}=$ $\tilde{n}$, say. That is, (i) $\frac{\partial f(n, k)}{\partial n}<0 \Leftrightarrow 0 \leq n<\tilde{n}$, (ii) $\frac{\partial f(n, k)}{\partial n}=0 \Leftrightarrow n=\tilde{n}$ and (iii) $\frac{\partial f(n, k)}{\partial n}>0 \Leftrightarrow \tilde{n}<n \leq 1$. 
(c) $f(0, k)>0, f(\tilde{n}, k)<0$ and $f(1, k)<0, \forall k \geq 2$.

From (a)-(c) it follows that, for any given $k(\geq 2)$, there exists a $n$, say $\hat{n}(k)$, such that (i) $f(n, k)>0$, if $n<\hat{n}(k)$; (ii) $f(n, k)=0$, if $n=\hat{n}(k)$ and (iii) $f(n, k)<0$, if $n>\hat{n}(k)$.

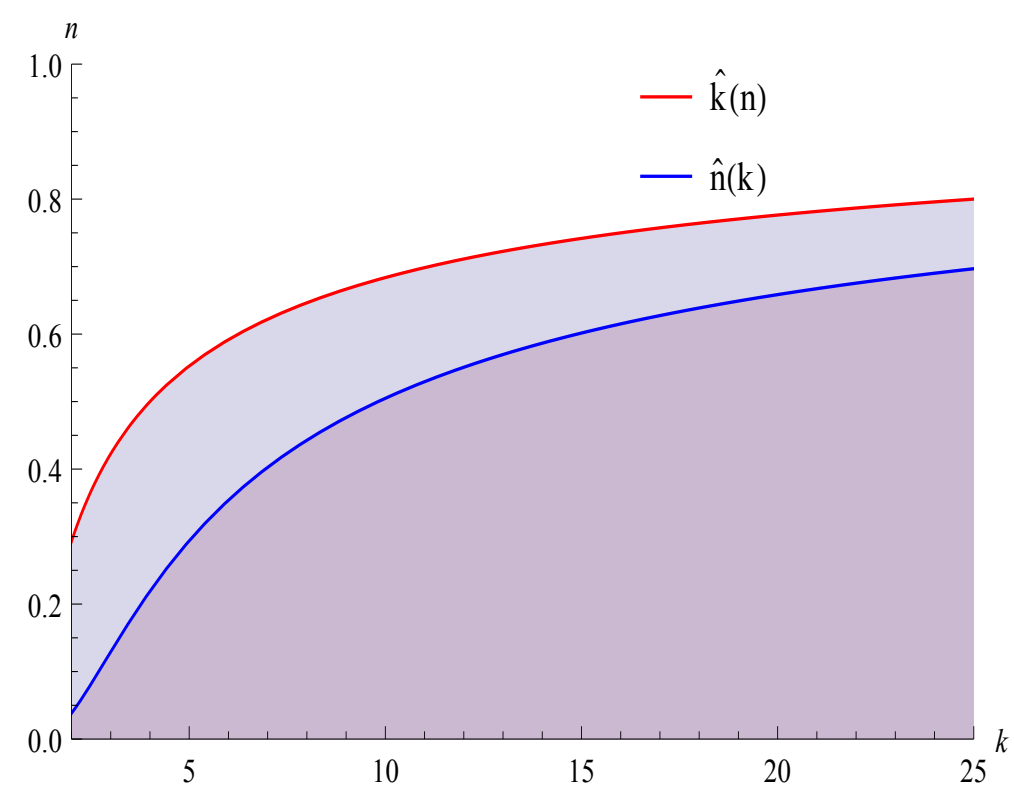

Figure 2: Stability of Collusion

Therefore, whenever there is an incentive to collude, as number of firms increases collusion becomes more (less) stable, if the strength of network externalities is greater (less) than a critical level $\hat{n}(k)$. Further, it can be checked that, $\frac{\partial \hat{n}(k)}{\partial k}>0$, i.e., the critical level of the strength of network externalities is higher in the case of larger number of firms. Figure 2 plots the curve $n=\hat{n}(k)$ along with the curve $k=\hat{k}(n)$ in $k n$-plane. In the shaded region bounded between the red and the blue curves, stability of collusion increases with the increase in number of firms in the market. In the shaded region below the blue curve, stability of collusion decreases with the increase in number of firms. That is, unless the strength of network externalities is very low, stability of collusion first increases and then decreases due to increase in number firms. Needless to mention here that, if $n=0$, more number of firms always makes collusion less stable. 
The above discussion introduces the following proposition.

Proposition 2: The effect of market concentration on collusion stability is non-monotonic, unless the strength of network externalities is very low.

\section{Conclusions}

This paper contributes to extending research on collusion stability in the presence of network effects. It shows that increasing network effects raise the gains from competition relative to the gains from collusion, reverting the standard result that collusion yields higher profits than competition when the number of firms is low enough. ${ }^{5}$ Moreover, in the parameter's space in which firms have the incentive to collude over an infinite time horizon, stability of collusion increases with the number of firms, as long as the latter is low enough and the strength of network externalities is not too low. This result crucially depends on the fact that network externalities directly impact the profits along the collusive path, while they affect the profits in the deviation and punishment stages via the number of firms. It follows that, under sufficiently large network effects, the number of firms has to be sufficiently low for the negative effect of lower market concentration on the deviation path profits to dominate its positive effect through the externality, and the collusive profits to be relatively higher, which makes collusion easier to sustain.

\footnotetext{
${ }^{5}$ Based on this result, the paper contributes to the debate on how firms earn lower profits by colluding, and acting as a monopolist, than by competing non-cooperatively. The original debate ensued from the seminal paper by Aumann (1973) who showed how, in an exchange market, collusion may be disadvantageous to traders as compared to the competitive outcome.
} 
- Aumann, R., 1973, Disadvantageous monopolies. Journal of Economic Theory 6, 1-11.

- Birke, D., 2009, The economics of networks: a survey of the empirical literature. Journal of Economic Surveys 23, 762-793.

- Boffa, F., Filistrucchi, L., 2014, Optimal Cartel Prices in two-sided market access, Working Papers 14-19. NET Institute, Stern School of Business, New York University.

- Brozen, Y., 1977, The concentration-collusion doctrine. Antitrust Law Journal 46, $826-863$

- Davies, S., Olczak, M., Coles, H., 2011, Tacit collusion, firm asymmetries and numbers: Evidence from EC merger cases. International Journal of Industrial Organization 29, 221-231.

- Devetag, G., 2003, Coordination and Information in Critical Mass Games: An Experimental Study. Experimental Economics 6, 53-73.

- Economides, N., 2009, Antitrust Issues In Network Industries, in: Kokkoris, I., Lianos, I. (Eds.), The Reform of EC Competition Law: New Challenges, Kluwer Law International, Alphen aan den Rijn, pp. 343-375.

- Fonseca, M.A., Normann, H.-T., 2008, Mergers asymmetries and collusion: experimental evidence, the Economic Journal 118, 387-400.

- Fraas, A. G., Greer, D. F., 1977, Market Structure and Price Collusion: An Empirical Analysis. Journal of Industrial Economics 26, 21-44.

- Friedman, J.W., 1971, A non-cooperative equilibrium for supergames. Review of Economic Studies 38, 1-12.

- Huck, S., Normann, H.T., Oechssler, J., 2004, Two are few and four are many: number effects in experimental oligopolies. Journal of Economic Behavior and Orga- 
nization 53, 435-446.

- Levenstein, M.C., Suslow, V.Y., 2006, What determines cartel success? Journal of Economic Literature 44, 43-95.

- Martin, S., 2006, Competition policy, collusion, and tacit collusion. International Journal of Industrial Organization 24, 1299-1332.

- Ruffle, B.J. Weiss, A., Etziony, A., 2015, The role of critical mass in establishing a successful network market: an experimental investigation. LCERPA Working Papers no. 0092, Wilfrid Laurier University.

- Ruhmer, I., 2011, Platform Collusion in Two-Sided Markets, mimeo, University of Mannheim.

- Selten, R., 1973, A simple model of imperfect competition, where 4 are few and 6 are many. International Journal of Game Theory 2, 141-201.

- Shy, O., 2011, A short survey of network economics. Review of Industrial Organization $38,119-149$. 